\title{
Rate of presentation and partial reinforcement effects in transfer of training
}

\author{
WAYNE R. FROHRING and L. R. GOULET, West Virginia \\ University, Morgantown, W. Va. 26506
}

Transfer effects in the $A-B, A-C$ paradigm were studied as a function of rate of presentation on List $1(1: 1,2: 2)$ and level of List-1 partial reinforcement (100\%,50\%,0\% ORM). Level of $\%$ ORM was varied in a mixed list. The results indicated greater negative transfer on List 2 after the fast (1:1) than the slow (2:2) rate of presentation on List 1 . In addition, the magnitude of negative transfer under each List-1 presentation rate was independent of level of List-1\% ORM. This was true even for the pairs assigned to the 0\% level of ORM where the possibility of any specific $(A-B)$ associative learning on List 1 was precluded. Interpretations of these results were discussed.

There is increasing interest in the effects of task variables in determining the direction and magnitude of transfer and retroaction. For example, List-1 response meaningfulness is directly related to the magnitude of the negative transfer in the A-B, A-C paradigm (Goulet, 1965; Jung, 1963). Furthermore, retroactive inhibition is substantially reduced in the same paradigm when the form class of the responses (e.g., letters, adjectives) is changed from List 1 to List 2 (Postman, Keppel, \& Stark, 1965).

The concern with the identification of task variables affecting transfer and retroaction has been paralleled by an increasing emphasis on identifying the basic unit of interference. In this framework, two hypotheses have been suggested. The first has been deemed specific interference by Ceraso (1964) where the unit of transfer is the specific stimulus-response pair. Thus, the unit of interference for a specific A-C pair on List 2 would be the A-B pair on List 1 which shared the same stimulus. The second hypothesis, deemed general interference by Ceraso, implies that the unit of interference on List 2 is the entire first list. Thus, learning of any A-C pair on List 2 would be subject to interference from all A-B pairs rather than from the single pair which shared the same stimulus on List 1 .

The concept of general interference finds indirect and direct support from a number of sources. For example, Goulet (1967) and Goulet, Meltzer, \& O'Shaunessy (1967) have found that negative transfer in the A-B, A-C paradigm is unaffected by partial reinforcement procedures implemented on List 1 which assured differential degrees of learning for individual sets of pairs. In other words, the magnitude of negative transfer on List 2 was independent of the degree of learning of specific pairs within the list. Similarly, Battig (1966) has found that the magnitude of negative transfer for $\mathrm{A}-\mathrm{C}$ pairs varied directly with the number of C-D (mixed-list) pairs in the list, transfer for the $\mathrm{A}-\mathrm{C}$ pairs shifting from negative to positive as the number of C-D pairs was increased from two to six.

Other evidence for general interference factors in retroactive inhibition is available. Ceraso (1964) has found that unlearning effects generalize to pairs which have an A-B, C-D relationship on List 1 and List 2 as long as some of the pairs in the mixed list had an A-B, A-C relationship on List 1 and List 2.

The present experiment was concerned with the effects of two variables on transfer. The first variable was level of List 1 partial reinforcement which was manipulated in terms of percentage of occurrence of response members (\% ORM). This technique involves deleting the response terms on a fixed percentage of the learning trials. This procedure effectively retards both response and associative learning in direct proportion to the percentage of trials that the responses are deleted. ORM was varied at three levels in a mixed list, $100 \%$, $50 \%$, and $0 \%$. In contrast to the $100 \%$ - and $50 \%$-ORM pairs, no associative learning for the $0 \%$ pairs was possible since only the stimuli for these pairs were shown during practice. Extended to its logical extreme, the specific interference hypothesis implies negative transfer for the $100 \%$ and $50 \%$ pairs, with no concomitant interference for the $0 \%$ pairs. The general interference hypothesis implies equal negative transfer for the $100 \%, 50 \%$, and $5 \%$ pairs because of generalization of interference effects to all pairs on List 2.

The second variable of concern was the effect of List-1 presentation rate. Goulet (1967) and Goulet et al (1967), have provided evidence suggesting that the number of List-1 practice trials, and not the degree of learning per se, influences the magnitude of negative transfer in the $A-B, A-C$ paradigm. If this hypothesis were correct, it would be plausible to expect greater negative transfer for the fast $(1: 1)$ rather than for a slower $(2: 2)$ rate of presentation when List-1 learning was carried to a common criterion for both presentation rates.

\section{DESIGN AND MATERIALS}

The basic design was a 2 by 2 by 3 "mixed" factorial with paradigm (A-B, A-C, experimental; and A-B, C-D, control) and rate of presentation on List $1(1: 1$ and $2: 2)$ as between-S factors and List-1 \% ORM $(100 \%, 50 \%, 0 \%)$ as a within-S factor. Each list consisted of nine adjective-nonsense syllable pairs. The adjectives (low similarity) were taken from Haagen's (1949) list, while the low-similarity nonsense syllables ( $\bar{X}$ AV = 93.55) were from Archer's (1960) norms. Two sets of lists were constructed for each paradigm and for each of List 1 and List 2 . The lists were constructed such that List 1 and List 2 were identical for each paradigm when pooled over lists.

Partial reinforcement was varied only on List 1 and was manipulated such that three pairs each on List 1 were randomly assigned to the $100 \%-, 50 \%-$, and $0 \%$-ORM levels. The responses under $100 \%$ ORM were paired with stimuli on each trial, while those assigned to the $50 \%$ level were paired with stimuli on a random two in each block of four trials. Under 0\% ORM, responses were never paired with stimuli during practice. As a control for pair difficulty, three alternate sets of each List 1 were constructed such that each pair was assigned to the $100 \%-, 50 \%$-, and $0 \%$-ORM levels in one of the sets.

The Ss were 48 general psychology students who participated in the experiment as partial fulfillment of a course requirement. Two Ss served in each subgroup. Twelve Ss served in each major treatment group (A-B, A-C vs A-B, C-D; $1: 1$ vs $2: 2$ presentation rate). The assignment to treatments was random with the restriction that equal numbers of Ss were assigned to each treatment before another replication block was begun. Most of the Ss were not naive to verbal learning but none had previous experience with \%-ORM manipulation.

All lists were presented on a Lafayette memory drum (anticipation method) in four random orders to prevent serial learning. The intertrial interval was $4 \mathrm{sec}$ on List 1 and List 2. The List-1 presentation rate was either $1: 1 \mathrm{sec}$ or $2: 2 \mathrm{sec}$. List 2 was always presented at a 2:2 rate. List 1 was practiced to a criterion of one errorless trial, excluding the $0 \%$ pairs which could not be learned. List 2 was practiced for 10 trials or one perfect repetition of the List, whichever occurred first. No partial reinforcement was involved on List 2. 
Table 1

Mean Correct Anticipations on List 2 for Trials $1-2$ and Trials 1-5

Trials 1-2

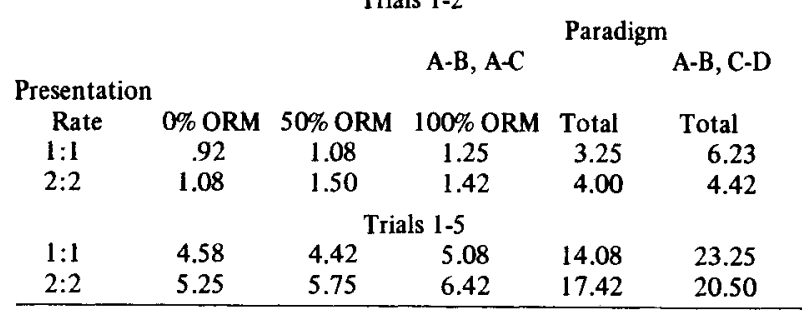

\section{RESULTS AND DISCUSSION}

\section{List-1 Learning}

All analyses involved the pooling of data over lists. As expected, the mean trials to criterion on List 1 varied directly with presentation rate $[F(1,44)=36.38, p<.001]$. The mean trials to criterion for the $1: 1$ rate was 35.79 , and for the $2: 2$ rate, 14.08 .

\section{List-2 Learning}

The primary data relate to acquisition on List 2 as a function of List-1 \% ORM and presentation rate. Table 1 presents mean correct anticipations for the A-B, A-C, and A-B, $C-D$ paradigms for these treatments on Trials $1-2$ and Trials 1-5. It should be noted that the pairs for the A-B, C-D treatments could not be subdivided according to List-1 $\%$-ORM level and therefore only the pooled mean for the nine pairs is presented for this treatment. Inspection of Table 1 reveals no systematic effects attributable to List-1 \%-ORM level. However, negative transfer was more pronounced for fast List-1 presentation rate. The statistical analysis for these data involved difference scores. That is, the mean correct anticipations of each $\mathrm{S}$ at each level of List-1 \% ORM in the A-B, A-C treatment was subtracted from the mean correct anticipations/3 (Table 1) under the relevant A-B, C-D treatment. The "mixed" factorial design (rate by \% ORM) revealed a statistically significant main effect for List-1 presentation rate for the data from Trials 1-2 and Trials 1-5 $[F(1,22)=6.24, p<.025$, and $5.39, p<.05$, respectively $]$. The data provide support for the assumption of transfer on List 2 being a direct function of the number of List-1 practice trials. The main effect for \% ORM was not statistically significant $(F s<1)$ for Trials $1-2$ and Trials $1-5$, respectively. The interaction also did not approach significance in either analysis $(\mathrm{Fs}<1)$ suggesting equivalent negative transfer at each level of \% ORM for the two rates of presentation. Statistical analyses were performed to determine whether statistically significant amounts of negative transfer were obtained under both rates of presentation for the A-B, A-C treatment. The analysis involved $t$ tests where the mean difference scores (A-B, A-C-A-B, C-D and pooled over \% ORM) were compared to the $S \bar{X}$ derived from the within-cell variance for the appropriate treatment in the above analysis of difference scores. For Trials $1-5, \mathrm{t}(11)=4.83, \mathrm{p}<.01$ at the $1: 1-\mathrm{sec}$ rate, $\mathrm{t}(11)=1.50, \mathrm{p}<.10$ for the $2: 2$ rate. The analyses for Trials $1-2, \mathrm{t}(11)=4.67, \mathrm{p}<.01$ for the $1: 1-\mathrm{sec}$ rate, and $t(11)=0.50(\mathrm{NS})$ for the $2: 2$ rate.

A final comment should be made regarding the effects of List-1 \% ORM on transfer. The $0 \%$ pairs did prevent Ss' associating a specific response to these stimuli, but did not restrict the possibility of some inadvertant associative learning during List-1 practice. As an example, any intralist errors that occur to the $0 \%$ stimuli could result in some associative learning. As a check on this possibility, the total intralist errors on List 1 were compared as a function of \% ORM and rate of presentation. The main effect for \% ORM was statistically significant $[F(2,88)=5.32, p<.025]$. The mean errors at the three levels of \% ORM (pooled over paradigm and rate) were $13.92,10.00$, and 9.75 for the $0 \%, 50 \%$, and $100 \%$-ORM pairs. These differences were attributable primarily to the differential opportunities to learn the pairs at the three levels of \% ORM. However, the mere occurrence of these errors to the stimuli under 0\% ORM does provide a possible explanation for the occurrence of negative transfer on List 2 for these pairs. In any event, the present data suggest that the occurrence of negative transfer is independent of specific associative (A-B) learning on List 1.

\section{REFERENCES}

ARCHER, E. J. A re-evaluation of the meaningfulness of all possible CVC trigrams. Psychological Monographs: General \& Applied, 1960, $74,(10$, Whole No. 497).

BATTIG, W. F. A shift from "negative" to "positive" transfer under the $A-C$ paradigm with increased number of C-D control pairs in a mixed list. Psychonomic Science, 1966, 4, 421-422.

CERASO, J. Specific interference in retroactive inhibition. Journal of Psy chology, 1964, 58, 65-77.

GOULET, L. R. Interlist response meaningfulness and transfer effects under the A-B, A-C paradigm. Journal of Experimental Psychology, 1965, 70, 264-269.

GOULET, L. R. Degree of learning and transfer of training. Psychonomic Science, $1967,8,245-246$.

GOULET, L. R., MELTZER, R. A., \& O'SHAUNESSY, K. K. Further data on degree of learning and transfer of training. Psychonomic Science, 1967, 9, 469-470.

HAAGEN, C. H. Synonymity, vividness, familiarity, and association values for 400 pairs of common adjectives. Journal of Psychology, $1949,30,185-200$.

JUNG, J. Effect of response meaningfulness $(\mathrm{m})$ on transfer of training under two different paradigms. Journal of Experimental Psychology, $1963,65,377-384$

POSTMAN, L., KEPPEL, G., \& STARK, K. Unlearning as a function of the relationship between successive response classes. Journal of Experimental Psy chology, 1965, 69, 111-1 18. NOTE

1. This research was supported in part by NIMH Grant MH-13515 to the junior author.

\section{(Continued from page 157)}

speed is held constant, but in which $E$ would vary TOT achievement, should provide some evidence on this possibility. Using inhibition theory as a guide, it would be predicted that reduced TOT would permit greater inhibition dissipation, leading to better performance in final practice.

\section{REFERENCES}

ADAMS, J. A. A source of decrement in psychomotor performance. Journal of Experimental Psychology, 1955, 49, 390-394.

AMMONS, R. B. Effects of pre-practice activities on rotary pursuit performance. Journal of Experimental Psychology, 1951, 41, 187-191.

CATAlano, J. F. Arousal as a factor in reminiscence. Perceptual \& Motor Skills, 1967, 24, 1171-1181.

DUNCAN, C. P. Visual and kinesthetic components of reactive inhibition. American Journal of Psychology, 1957, 70, 616-619.
HULL, C. L. Principles of behavior. New York: Appleton-Century, 1943. IRION, A. L., \& GUSTAFSON, L. M. Reminiscence in bilateral transfer. Journal of Experimental Psychology, 1952, 43, 321-323.

McBAIN, W. N. The use of magnetized tape recording in psychological laboratories. American Psychologist, 1956, 11, 202-203.

ROSENQUIST, $H$. S. The visual response component of rotary pursuit tracking. Perceptual \& Motor Skills, 1965, 21, 555-560.

\section{NOTE}

1. A version of this paper was presented November 2, 1968 at the annual meeting of the Psychonomic Society. Data was gathered for the study by Rodney De Angelis, with the support of Grant RG-138 from the faculty of The University of Akron. 